\title{
Human and Animal Thermophilic Campylobacter infections in East African countries: Epidemiology and Antibiogram
}

\author{
Erick VG Komba* \\ Department of Veterinary Medicine and Public Health, University of Agriculture, Tanzania
}

Received: September 12, 2017; Published: October 05, 2017

*Corresponding author: Erick VG Komba, Senior lecturer, Department of Veterinary Medicine and Public Health, College of Veterinary Medicine and Biomedical Sciences, Sokoine University of Agriculture, P.O. Box 3021, Morogoro, Tanzania, Tel: +255 713 584054; Email: babagrid@yahoo.com

Abstract

Purpose: Campylobacter mediated diarrhoea is a leading cause of gastroenteritis worldwide. The organisms colonize the gastrointestinal tract of different animal species without causing disease symptoms. Humans acquire infections through contact with or consumption of contaminated meat especially raw/undercooked poultry meat. The rapid emergence of antibiotic-resistant Campylobacter strains heightens the public health concern of the organisms. The aim of this review was to summarise information on the epidemiology and antibiogram of Campylobacter in humans and animals in East African countries.

Method: A structured literature search of PUBMED and Science Direct electronic databases.

Results: Forty reports on thermophilic Campylobacter were identified in four of the five East African countries in the following order; Kenya (16), Tanzania (17), Uganda (4) and Rwanda (3). No study was found to report thermophilic Campylobacter infections in either humans or animals in Burundi. Studies on animals reported colonization of both domestic and wild species. Of the studies that described Campylobacter infections in humans, both symptomatic and asymptomatic subjects were reported to be infected; with higher prevalence in subjects younger than five years old. Among isolates, some demonstrated antimicrobial resistance.

Conclusion: Available information for both human and animal Campylobacteriosis in the region is however sparse thus calling for more research to better understand the epidemiology of infections caused by the organism including clonal dependence and independence of human and animal derived isolates. This understanding will help researchers and health program developers in designing and implementing effective control strategies. Since the organism is zoonotic its control strategies should adopt the "One Health" approach involving collaborative efforts from veterinary and human medicine.

Keywords : Adults; Children; Campylobacter; Chickens; Diarrhoea; Food animals; Wild animals

Abbreviations : CEB: Campylobacter Enrichment Broth; CCDA: Charcoal Cefaperazone Deoxycholate Agar; PCR: Polymerase Chain Reaction; MALDI-TOF: Matrix-Assisted Laser Desorption/Ionization Time of Flight

\section{Introduction}

Campylobacter is recognized as a major cause of human acute food-borne bacterial enteritis both in developed and developing countries [1]. The organism exists as normal flora in the intestinal tracts of many domesticated and wild avian and mammalian species [2-4]. The colonization, by these organisms, of animals used in food production (including poultry, cattle, sheep and swine) and rapid emergence of antibiotic-resistant Campylobacter strains is currently of particular public health concern [5]. Animals carrying Campylobacter pose a risk for human infections from contamination of carcasses, milk, and water through wastes and slurries [6-9]. Human illness, frequently associated with Campylobacter jejuni and Campylobacter coli, is characterized by watery to bloody diarrhoea, abdominal pain, fever, malaise, nausea, presence of leukocytes and red blood cells in faeces and/or vomiting [10,11]; and may persist for a week or even longer [12]. Campylobacter infections can also develop to Guillain-Barre' syndrome (GBS), an autoimmune-mediated neurodegenerative disorder which causes acute neuromuscular paralysis [13,14].

Rational control programs for many infectious diseases require a thorough understanding of their epidemiologies. The present paper provides a review on Campylobacter studies conducted in East African countries, both in humans and animals. Though 
limited, reviewed information will enhance our understanding of the epidemiology and more importantly antibiotic resistance profiles of both human and animal derived Campylobacter isolates in the region. This will provide a platform to guide the process of devising holistic control strategies for this zoonotic pathogen.

\section{Methods}

We searched for the papers which described Campylobacter infections in East African countries (Tanzania, Kenya, Uganda, Rwanda and Burundi) in the Pub Med database provided by the United States National Library of Medicine and Science Direct database provided by Elsevier. Reference lists of initially retrieved articles were searched to identify additional studies. In total 38 papers describing Campylobacter infections in East African countries, published from 1983 to the time of the searches, were collected and summarized in this review. All reviewed papers originated from research activities and none from routine diagnosis. During the review of the literature, the data extracted included sample sources and sizes, identification methods, isolation rates and antibiogram of the tested isolates in some of the studies.

\section{Results and Discussion}

\section{Sample types and Sources}

Faecal samples represent the specimen of choice for the isolation of Campylobacter species in individuals presenting with gastrointestinal symptoms [15]. In the present review, studies on Campylobacter in humans involved collection of faecal samples from individuals complaining of enteric problems (symptomatic) seeking for medical services in health facilities within the study areas. In some studies involving children in Tanzania [16-18] and Kenya [19,20] faecal samples were also collected from asymptomatic human subjects. In most of the studies the samples were obtained as whole stool specimens but in some few occasions, again for studies involving children, rectal swabs were collected $[16,17]$.

Studies on detection of Campylobacter in animals involved collection of fecal samples from goats, chimpanzees, cattle, ducks, crows, chickens, gorillas, mice, sheep and pigs. From avians the samples were obtained either through collecting cloacal swabs (live birds), collection of droppings in poultry houses or obtaining caecal contents from intestines of slaughtered birds [21-24]. Available reports on investigations of contamination levels of meat products in Tanzania involved collection of swabs from cattle [25] and pig [26] carcasses. In Kenya such investigations involved collection of swabs from dressed chicken and beef meat samples [27].

\section{Handling and transportation of Samples}

The viability of Campylobacter spp. can be affected by environmental conditions such as dehydration and oxygen and both freezing and high temperatures [28,29]. During sample collection for detection of these organisms, therefore, transport to the laboratory should be as fast as possible and preferably in suitable transport media, in order to protect the cells from drying out and from the toxic effect of oxygen [28,29]. In the reviewed studies sample collection took into account the fastidious nature of the micro-organism, and so ensured favourable transport conditions. While some studies transported the samples in CaryBlair's medium [23,30], a study by Kaur et al. [31] Adopted the use of brucella broth containing $20 \%$ glycerol. Transportation of the samples involved the cold chain.

\section{Laboratory Diagnosis}

\section{Detection of Campylobacter}

There exist several protocols for detection of Campylobacter species from different samples. Conventional diagnostic procedures, such as culture and microscopy are however routinely used in most medical microbiology laboratories in developing countries for detection of enteric pathogens including Campylobacter [32]. These procedures include enrichment steps, use of selective culture media, biochemical identification, sero-typing, and resistance resting [32]. The methods are useful for characterization of organisms at species and subspecies levels [33]. Molecular methods are known to provide a means for sensitive and rapid detection of enteric pathogens; but their application is limited by their high costs, inhibition caused by faecal constituents [34], and the need for specialized laboratories and equipment.

The detection of Campylobacter organisms in most of the investigations reported by the papers reviewed in this article employed mainly culture methods, particularly the qualitative (enrichment) method and direct plating method. In Tanzania, however, a study conducted in Chimpanzees [31] employed molecular biological method in combination with enrichment culture. The enrichment media employed in most of the cited studies were mainly Bolton broth, Campylobacter enrichment broth (CEB) and Preston broth. The isolation medium employed was mainly charcoal cefaperazone deoxycholate agar (CCDA). For some studies in Kenya, however, Skirrow's selective medium [35-38]; and antibiotic containing Campylobacter agar [39] and blood agar [30] were used. The use of non selective Trypticase soy agar containing $5 \%$ sheep blood [31] and blood agar [18,24]; together with $0.45 \mu \mathrm{m}$ filters was also reported in some investigations in Tanzania.

A comparative study by Jacob et al. [24] revealed that the method combining filtration and culture on antibiotic-free blood agar (the Cape Town protocol) resulted into significantly higher prevalence than culture on antibiotic containing agar (the Skirrow's protocol). The superiority of the Cape Town protocol over the Skirrow's protocol has been documented previously in South Africa [40]. The authors pointed out that the protocol increases both the number of strains and the number of Campylobacter spp. and species of the related genera Arcobacter and Helicobacter isolated from stools.

\section{Identification and typing of Campylobacter}

In the reviewed studies Campylobacter species were mainly identified based on growth temperature preferences, growth in microaerophilic environment, colonial morphology, Gram staining and biochemical characterization of urease, catalase, and oxidase production, as well as sensitivity to nalidixic acid and cephalothin. The studies adopted hippurate hydrolysis test to distinguish 
between C. jejuni and other species. According to Nakari et al. [41], however, proper phenotypic identification of Campylobacter isolates, especially differentiation between C. jejuni and C. coli based on the hippurate test, might be difficult and could result in false results. It has also been previously reported by Rönner and Lindmark [42] that hippurate hydrolysis test used for species identification between C. jejuni and C. coli is not always reliable.

This may be supported by findings in one of the cited studies in this review [22] in which Polymerase Chain Reaction (PCR) confirmed only $74.1 \%$ of 243 isolates identified by hippurate hydrolysis test to be C. jejuni. Some few studies adopted serotyping method [16] and DNA based molecular techniques [18,22,23,31] to identify and type Campylobacter isolates. A study by Komba et al. [18] also adopted a spectrophotometric method, Matrixassisted laser desorption/ionization time of flight (MALDI-TOF) spectrophotometry technique in identification of thermophilic Campylobacter.

\section{Thermophilic Campylobacter in Humans}

Several studies have reported Campylobacter infections in humans in East African countries with point prevalence ranging from $6.67 \%$ (Rwanda) to $9.3 \%$ (Uganda) (Table 1). The most common clinical sign in symptomatic subjects was acute gastroenteritis characterized by diarrhoea which in some cases was bloody as reported in Kenya by Brooks et al. [43]. consistently, studies have reported higher prevalence in young individuals, particularly those under the age of 5 years, as compared to adults. It has been mentioned previously that in developing countries campylobacteriosis has been considered as a disease of young children [44,45]; while in industrialized countries it is a disease mainly of adults [46]. This observation can however partly be contributed by the fact that in developing countries children are urgently taken to health facilities even for mild symptoms as opposed to adults. Some studies in Kenya [19] and Tanzania [23] have shown male preponderance in human Campylobacter infections. However a study carried out in Mombasa, Kenya [36], found no significant differences in prevalence between males and females.

Studies involving symptomatic and asymptomatic human subjects found no significant differences in prevalence of Campylobacter infections between the two groups; both in Kenya $[19,20]$ and Tanzania $[16,47,18]$. However in a study by Lindblom et al. [16] analysis of results for a stratum of children under the age of 18 months found a high prevalence of Campylobacter infection in symptomatic subjects as opposed to asymptomatic counterparts. These findings are in line with those obtained by other investigators elsewhere in other developing countries who noticed that Campylobacter is as common in faeces from symptomatic children as from asymptomatic ones but they found a difference among those under the age of 18 months [48-50]. The reason for a high prevalence of Campylobacter infection in symptomatic subjects under 18 months as opposed to asymptomatic counterparts is induced immunity [51].
In most of the studies carried out in the East African countries, C. jejuni was the dominant species isolated and C. coli was less frequently isolated, with the ratio of $\mathrm{C}$. coli to $\mathrm{C}$. jejuni varying considerably being $1.06: 1$ to $28.41: 1$ among studies as well as among countries. According to Tadesse et al. [52] Campylobacter species that are most commonly associated with human illness are C. jejuni and C. coli. The author's further point out that C. jejuni is responsible for up to $90 \%$ of the cases of human infections, whereas C. coli is responsible for the majority of the remaining human cases. Their observation supports the findings of the reviewed studies in this article (Table 1).

Table 1: Prevalence of Campylobacter infections in humans in East African countries.

\begin{tabular}{|c|c|c|c|}
\hline Country & $\begin{array}{l}\text { Age group } \\
\text { (Sample } \\
\text { size) }\end{array}$ & $\begin{array}{c}\text { Prevalence } \\
(\%)\end{array}$ & References \\
\hline \multirow{2}{*}{ Kenya } & $\begin{array}{l}\text { Children } \\
(10816)\end{array}$ & $\begin{array}{c}7.30(0.00- \\
17.00)\end{array}$ & $\begin{array}{c}{[19,20,30,35,36 ;} \\
37,38,39,43,53,54,55,56]\end{array}$ \\
\hline & Adults (953) & $\begin{array}{c}7.53(3.50- \\
10.00)\end{array}$ & {$[19,2030]$} \\
\hline \multirow{2}{*}{ Tanzania } & $\begin{array}{l}\text { Children } \\
(2340)\end{array}$ & $\begin{array}{c}9.64(0.00- \\
20.00)\end{array}$ & $\begin{array}{c}{[16,17,} \\
22,23,24,47,57,58,59]\end{array}$ \\
\hline & Adults (1622) & $\begin{array}{l}6.93(1.00 \\
-21.60)\end{array}$ & {$[16,18,22,24,59]$} \\
\hline Uganda & $\begin{array}{l}\text { Children } \\
(226)\end{array}$ & 9.30 & {$[60]$} \\
\hline \multirow{2}{*}{ Rwanda } & $\begin{array}{l}\text { Children } \\
\text { (102) }\end{array}$ & 11.00 & [61] \\
\hline & Adults (98) & $\begin{array}{c}4.65(2.63- \\
6.67)\end{array}$ & {$[62,63]$} \\
\hline
\end{tabular}

\section{Thermophilic Campylobacter in Poultry}

To date thermophilic Campylobacter remain the most common cause of acute bacterial enteritis in humans worldwide [53-63], where the ingestion of contaminated chicken or poor food handling practices associated with raw chicken represents the primary route of transmission [64]. Despite all the acquired knowledge on Campylobacter organisms, including the publication of the complete genome sequence for $\mathrm{C}$. jejuni, the prevalence of human infections remains high and there are still major problems in producing Campylobacter free poultry [65]. The ability of these bacteria to grow at $420 \mathrm{C}$ suggests their adaptation to the gut of most avian species [66]. Of the avian species broiler chickens are commonly regarded as a natural host for this zoonotic pathogen and infected birds carry a very high C. jejuni load in their gastrointestinal tracts, especially the caeca [67]. Colonization of broiler chicks is known to occur at a very early stage in their life and prevalence of colonization among poultry flocks increases gradually with age until slaughter [68] and can reach up to $100 \%$ in some areas [69].

In the East African region, reports on colonization of poultry with Campylobacter are available in Tanzania and Kenya, studies being conducted in chickens as well as ducks. In Tanzania, Nonga and Muhairwa [70] found that $80 \%$ of the sampled ducks $(\mathrm{n}=90)$ were colonized with Campylobacter organisms; where as 
in Kenya Turkson et al. [30] isolated the organisms from $29.4 \%$ of the screened ducks $(n=85)$. The use of intestinal contents in a study conducted in Tanzania may have attributed to a higher prevalence as opposed to a study in Kenya where cloacal swabs were collected. The prevalence of the organisms in chickens is presented in (Table 2). In all the studies C. jejuni accounted for the majority of Campylobacter detected followed by C. coli. The findings of these studies indicate the role of poultry in the epidemiology of Campylobacteriosis (Table 2).

Table 2 : Colonization of chickens by Campylobacter in some East African countries.

\begin{tabular}{|c|c|c|c|}
\hline Country & $\begin{array}{c}\text { Chicken type } \\
\text { (Sample size) }\end{array}$ & $\begin{array}{c}\text { Prevalence } \\
\text { (\%) }\end{array}$ & References \\
\hline \multirow{2}{*}{ Kenya } & Broilers (226) & 51.5 & {$[30]$} \\
\hline \multirow{5}{*}{ Tanzania } & Broilers (768) & $\begin{array}{c}55.48(26.40- \\
77.80)\end{array}$ & {$[21,22,23,24]$} \\
\cline { 2 - 4 } & $\begin{array}{c}\text { Free ranging } \\
\text { chickens (450) }\end{array}$ & $\begin{array}{c}75.83(75.00- \\
76.49)\end{array}$ & {$[21,22,23]$} \\
\cline { 2 - 4 } & Layers (308) & $\begin{array}{c}23.45(22.70- \\
24.20)\end{array}$ & {$[21,22]$} \\
\hline
\end{tabular}

\section{Thermophilic Campylobacter in other Food Animals}

Many different animal species maintain Campylobacter species without showing clinical signs. Although the role of these organisms as primary pathogens in farm animals is uncertain, they are of major public health importance [54]. The present review found some studies reporting colonization of farm animals with Campylobacter organisms. A study in Kenya by Turkson et al. [30] found prevalence of 55.1\%, 44.0\%, 6.3\%, 5.8\% and $2.0 \%$ in diarrhoeic pigs $(n=6)$, healthy pigs $(n=150)$, healthy goats $(n=128)$, healthy cattle $(n=121)$ and healthy sheep $(n=98)$ respectively. In Tanzania goats, pigs, cattle and sheep were found colonized in the order of $4.65 \%[57,71], 32.2 \%[26,57,71], 2.25 \%[57,59]$ and $31.6 \%$ [72] respectively.

In most of the studies in both countries, C. jejuni accounted for the majority of Campylobacter detected in farm animals including pigs. These findings in pigs contradict those of other studies which indicated that Campylobacter infections in pigs show a dominance of C. coli [73-76]. Nevertheless, the finding is supported by some other studies which have found a dominance of $\mathrm{C}$. jejuni in pigs $[77,78]$. Given these contradictory data, the risk of food borne disease associated with this animal species is not clear but cannot be ignored [79].

. Studies in Tanzania indicated that C. jejuni and C. coli were isolated with similar magnitude in goats. The authors $[57,71]$ found that only goats in households keeping other animals particularly pigs and poultry were positive, carrying isolates similar to those found in these other animals. They concluded that goats are not natural hosts for Campylobacter and those pigs and poultry serve as main sources of infection

\section{Thermophilic Campylobacter in Non Food and Laboratory Animals}

In Tanzania Laboratory animals were involved in a study on thermophilic Campylobacter where 30 guinea pigs, 160 mice, 34 rabbits and 242 rats were sampled. Colonization with the organism was detected in $26.7 \%$ of the guinea pigs and $1.2 \%$ of the rats [72]. In the same country colonization of horses with thermophilic Campylobacter was detected at a tune of $60 \%(n=5)$ [72].

\section{Thermophilic Campylobacter in Wild Birds}

Campylobacter species colonize a range of hosts, including domestic animals and wild birds. Campylobacter carrying wild birds have higher chances of contaminating water sources, the environment and food; and eventually transmit the pathogens to humans and poultry $[80,81]$. In a study conducted in Sweden by Waldenstrom et al. [82], which reported the prevalence of Campylobacter spp. by ecological guilds based on feeding habits; it was reported that migrating birds were commonly infected by Campylobacter spp. A study in Nigeria revealed phenotypical and genotypical similarities among C. jejuni isolates from free flying birds and humans [83]. Several other studies conducted elsewhere in other countries reported occurrence of Campylobacter, particularly C. jejuni, in crows [84-86].

In Tanzania a study by Mdegela et al. [22] isolated thermophilic Campylobacter from crows at $72.8 \%(\mathrm{n}=22)$. The obtained high prevalence is of epidemiological and public health significance, as it highlights the possibility for crows serving as among important sources of thermophilic Campylobacter in humans and chickens in Tanzania. It has been previously suggested that, free flying birds including crows around poultry farms may transmit thermophilic Campylobacter to chickens if they get access to the rearing houses [80,87]. A study on Campylobacter infections in vervet monkeys in another East African country, Kenya [88] incriminated birds, the main natural carriers of Campylobacter spp [89], as one of the possible sources of infections to the monkeys through environmental contamination with their droppings.

\section{Thermophilic Campylobacter in wild mammals (mice and non-human primates)}

Investigation and understanding of wildlife diseases are vital aspects of natural resource management programs [90]. In the current situation where humans are in frequent interactions with wildlife for different reasons, surveillance and reporting of infectious agents in these animal populations are increasingly important [31]. In this review five studies were conducted in Tanzania (2), Kenya (1) and Uganda (2) to investigate on colonization of wild mammals with Campylobacter organisms. In Uganda studies involving sampling of mountain gorillas (Gorilla beringei beringei) by Nizeyi et al. [91] and Kalema-Zikusoka et al. [92] reported the prevalence of Campylobacter infection at $19 \%$ and $8 \%$ respectively.

A study on Campylobacter infection in wild mammals in Kenya [88] involved sampling of diarrheic vervet monkeys. Campylobacter jejuni was isolated from all the sampled subjects $(\mathrm{n}=8)$. Although captive and free-living wild animals can be healthy asymptomatic 
carriers of Campylobacter spp., the authors linked infection with the organisms to a fatal outbreak in the study subjects. Taema et al [90] points out that several other previous research reports showed that Campylobacter spp. were linked to many disease outbreaks in semi-wild and wild animals, with negative effects on the health, productivity, and welfare of a variety of species. In Tanzania, a pilot study by Jiwa et al. [57] isolated C. jejuni from $40 \%(n=20)$ of field mice (Mastomis nataliensis). The authors claimed conformity of biotype profiles of the mice isolates with profiles of human isolates obtained in the same study location.

Another study in the same country in which human-habituated chimpanzees (Pan troglodytes schweinfurthii) were the subjects [31], a novel species of Campylobacter, Campylobacter troglodytis, was isolated from the feces of $34 \%(n=56)$ of the study subjects. The authors characterized the organism by phenotypic, genotypic, and phylogenetic analyses. The authors however could not determine whether the organism was pathogenic to chimpanzees or not. The ability of this novel Campylobacter to colonize humans and cause enteric disease is an area which needs further investigation.

\section{Contamination of meat products with Campylobacter}

Poor slaughter methods and unhygienic meat handling may constitute a potential risk of infections to humans [93]. As Campylobacter are among organisms with enteric predilection and stay in the intestinal contents, cross-contamination of meat can originate from the faeces of the same animal or different animals through the slaughterhouse environment or equipment especially during flaying, evisceration or from cross contamination from hide to carcass $[94,95]$. The use of contaminated water to wash carcasses may also be a source of meat contamination with infectious microorganisms.

Literature search for the present review identified three studies which assessed contamination levels of animal meat products in the East African region. A survey in Tanzania revealed cattle carcass contamination level of 9.3\% [25], where as a study in Kenya [27] found beef contamination with Campylobacter organisms at $2 \%(n=50)$. Compared with other regions (Asia, Europe and America), many more studies have reported variable levels of cattle carcasses contamination with Campylobacter organisms [95-98]. A study on chicken carcass contamination in Kenya [27] found a point prevalence of Campylobacter organisms on dressed chicken samples of $77 \%(n=100)$. The authors reported, C. jejuni, C. coli and $\mathrm{C}$. laridis in chicken carcasses at 59\%,39\%, 2\% respectively. According to them isolation (85.3\%) was higher in chickens that have stayed more than 24 hours since slaughter.

Campylobacter jejuni biotype 1 also featured in a study that isolated the organisms from faecal contents. A survey in Tanzania revealed contamination level in pig carcasses at $10.6 \%$ [26]. The level of contamination obtained in this study was comparable to findings obtained elsewhere Aquino et al. (2002). It was however fairly low when compared to studies conducted by Steinhauserova et al. [93] and Malakauskas et al. [99] who reported higher pig carcass contamination ranging from 34-63.6\%. In contrast, studies in developed countries; Poland [100], Belgium [101], and Sweden [102] reported low magnitude of carcass contamination.
Differences in Campylobacter isolation from carcasses may be influenced by the prevalence in slaughter animals, abattoir hygiene, slaughter and dressing methods, sampling and analysis methods and sampling plan. Findings from two studies in Tanzania and Kenya incriminated gut content as the major source of carcass contamination. It is suggested from these findings that poultry meat, pork and beef play an important role in the epidemiology of Campylobacteriosis. The findings suggest a need for increased surveillance of Campylobacter in food chains in order to better protect consumers.

\section{Seasonal patterns of Campylobacter infections}

Understanding seasonal trends in Campylobacter infections may help in analysis of the seasonal differences in the risks for contracting campylobacteriosis. Evidence of seasonal peaks in human Campylobacter infection has been observed in several European countries [103-107]. Several other investigations have reported seasonality of Campylobacter colonization in poultry with peaks observed in the summer [108-115]. Moreover studies have shown seasonality in the isolation of Campylobacter from retail chicken [116-118]. These findings suggest that climatic factors may be important for Campylobacter infections in broilers and humans in these countries.

In the present review, two studies conducted in Tanzania attempted to investigate the seasonal variation on human Campylobacter infections [16,58], but did not find any significant difference. In Kenya a study by Shimotori et al. [36] found varying human colonization of $17 \%, 5.4 \%$ and $12.2 \%$ in July, September and November respectively. However, the authors did not draw any conclusion regarding seasonal variation. The rest of the studies in the region were carried out in different seasons but yet yielded more or less similar prevalence. On the other hand studies on Campylobacter colonization in animals did not strive to investigate the seasonal influence. Similarly, despite being conducted in different seasons, they produced more or less similar results. Previously, however, a study in Zaire (a Central African country) reported high prevalence of Campylobacter infections in humans during the wet season [119].

\section{Antimicrobial resistance profiles of Campylobacter Isolates}

The use of large amount of antimicrobial agents in modern production animals to control infections tends to select for resistance in the zoonotic bacteria and thereby posing a risk for human health [120-122]. As with several other bacteria, Campylobacter with resistance to antimicrobial agents have been reported in both developed and developing countries. The situation is worse in developing countries where there is widespread and uncontrolled use of antibiotics. Studies indicate an upward trend of Campylobacter resistance to antibiotics with varying patterns being seen in different countries and regions $[5,123]$. A number of studies in East African countries have addressed the issue of antimicrobial resistance in the organisms. In Tanzania studies on both animals [70,72] and humans [18] report antimicrobial resistance among thermophilic Campylobacter isolates. 
Different proportions of resistant isolates have been observed including resistance to fluoroquinolones and macrolides, the drugs of choice for treatment of human Campylobacteriosis. Low levels of resistance have however been reported to be at lower levels for these drugs. In Uganda Mshana et al. [60] reported resistance of human derived Campylobacters to Ampicillin.

In Kenya resistance of human Campylobacter isolates was revealed on metronidazole [30]. In this country an observed sensitivity to erythromycin by $100 \%$ of the tested isolates [19] dropped to $48 \%$ [43] of the isolates in 23 years period. No reason was however raised as an attribute to this observation. Resistance of various proportions of tested isolates to Tetracycline, Clindamycin, Nalidixic acid [43], kanamycin, Sulphafurazole, Chloramphenical, Cotrimoxazole [19] and Trimethoprim-sulfamethoxazole $[20,43]$ have been reported in the country. Elsewhere C. jejuni has been found to be sensitive to several classes of antibiotics, including macrolides (especially erythromycin), which have been traditionally been utilized as first-line therapy, and quinolones such as ciprofloxacin [5].

However, quinolone resistance in Campylobacter is a rapidly emerging global problem and high levels have been documented in Thailand [124], Spain [125], Hong Kong [126], and India [127]. The widespread use of fluoroquinolones in clinical practice and possible utilization in veterinary practice could be contributing factors for these high levels of ciprofloxacin resistance. Available data on tetracycline show high levels of resistance with an upward increase over time [128-130]. The pattern is probably an attribute of persistent use of tetracyclines in animal husbandry. A described natural horizontal transfer of tetracycline resistance gene (tet(0) gene) without antimicrobial selection pressure between C. jejuni in the digestive tract of chickens [131] may also explain these high rates of tetracycline resistance.

\section{Conclusion}

In this paper, we reviewed published papers on epidemiology and antibiogram of Campylobacter in humans and different animal species in East African countries. The available information provides enough evidence of existence of Campylobacter infections both in humans and animals in the region, and highlights their public health implications. Colonization of wild birds and mammals (non human primates inclusive) heightens the concern as some of these are in close proximity with humans. Though limited, investigations on antimicrobial resistance revealed existence of the problem. Controlling infections by the organism requires adoption of 'One Health' concept, the worldwide strategy for control of zoonoses.

One of the challenges for researchers in the region countries would be to conduct further work using the more sensitive DNA based techniques leading to validation of clonal independence of the isolates circulating in animals (including the wild) and humans. There is also much to be done in the region in order to understand the pattern and trends of antibiotic resistance in Campylobacter isolates of both human and animal origin. Furthermore, environmental reservoirs of Campylobacter and risk factors for human infections with Campylobacter need to be investigated. The present situation, in which proper countermeasures are lacking, warrants attention to be paid for the sanitary handling of animal products particularly poultry. Risks resulting from proximity with wild animals, more so with non human primates should seriously be addressed. The novel Campylobacter species isolated from the chimpanzees (in Tanzania) warrants further studies especially on its ability to colonize humans and its pathogenicity both in chimpanzees and humans.

\section{References}

1. Rzewuska K, Korsak D, Maćkiw E (2010) Antibiotic resistance of bacteria Campylobacter sp. Przegląd Epidemiologiczny 64(1): 63-68.

2. Ketley JM (1997) Pathogenesis of enteric infection by Campylobacter. Microbiology 143: 5-21.

3. Takamiya M, Ozen A, Rasmussen M, Alter T, Gilbert T, et al. (2011) Genome Sequence of Campylobacter jejuni strain 327, a strain isolated from a turkey slaughterhouse. Standards in Genomic Sciences 4(2): 113-122.

4. Cody AJ, Mc Carthy NM, Wimalarathna HL, Colles FM, Clark L, et al. (2012) A Longitudinal 6-Year Study of the Molecular Epidemiology of Clinical Campylobacter Isolates in Oxfordshire, United Kingdom. Journal of Clinical Microbiology 50(10): 3193-3201.

5. Moore JE, Corcoran D, Dooley JS, Fanning S, Lucey B, et al. (2005) Campylobacter. Veterinary Research 36(3): 351-382.

6. Newell DG, Fearnley C (2003) Sources of Campylobacter colonization in broiler chickens. Applied and Environmental Microbiology 69(8): 4343-4351.

7. Gilpin BJ, Scholes P, Robson B, Savill MG (2008) The transmission of thermotolerant Campylobacter spp. to people living or working on dairy farms in New Zealand. Zoonoses Public Health 55(7): 352-360.

8. Ahmed W, Sawant S, Huygens F, Goonetilleke A, Gardner T (2009) Prevalence and occurrence of zoonotic bacterial pathogens in surface waters determined by quantitative PCR. Water Research 43(19): 4918-4928.

9. Pepe T, De Dominicis R, Esposito G, Ventrone I, Fratamico PM, et al. (2009) Detection of Campylobacter from poultry carcass skin samples at slaughter in Southern Italy. Journal of Food Protection 72(8): 17181721.

10. Skirrow MB, Blaser MJ (2000) Clinical aspects of Campylobacter infection. In: Nachamkin I, Blaser MJ (eds), Campylobacter, $2^{\text {nd }}$ Edn, USA pp. 69-88.

11. Heymann DL (2008) Control of Communicable Diseases Manual. $19^{\text {th }}$ edn, pp. 94-98. American Public Health Association, USA.

12. Butzler JP, Oosterom J (1991) Campylobacter: pathogenicity and significance in foods. International Journal of Food Microbiology 12(1): 1-8.

13. Nachamkin I, Allos BM, Ho T (1998) Campylobacter species and Guillain-Barre syndrome. Clinical Microbiology Reviews 11(3): 555567.

14. Parkhill J, Wren BW, Mungall K, Ketley JM, Churcher C, et al. (2000) The genome sequence of the food-borne pathogen Campylobacter jejuni reveals hypervariable sequences. Nature 403(6770): 665-668.

15. Senok AC, Botta GA (2009) Campylobacter enteritis in the Arabian Gulf. Journal of Infection in Developing Countries 3(2): 74-82.

16. Lindblom GB, Ahren C, Changalucha J, Gabone R, Kaijser B, et al. (1995) Campylobacter jejuni/coli and enterotoxigenic Escherichia coli (ETEC) in faeces from children and adults in Tanzania. Scandinavian Journal of Infectious Diseases 27(6): 589-593. 
17. Kingamkono R, Sjogren E, Svanberg U (1999) Enteropathogenic bacteria in faecal swabs of young childrenfed on lactic acid-fermented cereal gruels. Epidemiology and Infection 122(1): 23-32.

18. Komba EVG, Mdegela RH, Msoffe PLM, Nielsen LN, Ingmer H (2015) Prevalence, Antimicrobial Resistance and Risk Factors for Thermophilic Campylobacter Infections in Symptomatic and Asymptomatic Humans in Tanzania. Zoonoses and Public Health 62(7): 557-568

19. Wamola IA, Mirza NB, Ngugi JM, Bwibo NO (1983) Campylobacter gastroenteritis in Nairobi. East African Medical Journal 60(3): 146149.

20. Shapiro RL, Kumar L, Phillips Howard P, Wells JG, Adcock P, et al. (2001) Antimicrobial-Resistant Bacterial Diarrhea in Rural Western Kenya. Journal of Infectious Diseases 183(11): 1701-1704.

21. Kazwala RR, Jiwa SFH, Nkya AE (1993) The role of management systems in the epidemiology of thermophilic Campylobacters among poultry in Eastern zone of Tanzania. Epidenmiology and Infection 110(2): 273-278.

22. Mdegela RH, Nonga HE, Ngowi HA, Kazwala RR (2006) Prevalence of Thermophilic Campylobacter Infections in Humans, Chickens and Crows in Morogoro, Tanzania. Journal of Veterinary Medicinr B infect Dis Vet Public Health 53(3): 116-121.

23. Chuma IS (2009) Prevalence, risk factors and genetic relatedness among thermophilic Campylobacter from humans and chickens using RAPD-PCR in Morogoro, Tanzania, pp. 112.

24. Jacob P, Mdegela RH, Nonga HE (2011) Comparison of Cape Town and Skirrow's Campylobacter isolation protocols in humans and broilers in Morogoro, Tanzania. Tropical Animal Health and Production 43(5): 1007-1013.

25. Nonga HE, Sells P, Karimuribo ED (2009) Occurrences of thermophilic Campylobacter in cattle slaughtered at Morogoro municipal abattoir, Tanzania. Tropical Animal Health and Production 42(1): 73-78.

26. Mdegela RH, Laurence K, Jacob P, Nonga HE (2011) Occurrences of thermophilic Campylobacter in pigs slaughtered at Morogoro slaughter slabs, Tanzania. Tropical Animal Health Production 43(1): 83-87.

27. Osano O, Arimi S (1999) Retail poultry and beef as source of Campylobacter jejuni. East African Medical Journal 76(3): 141-143.

28. Cary SG, EB Blair (1964) new transport medium for shipment of clinical specimens. Journal of Bacteriology 88: 96-98.

29. Luechtefeld NW, Wang W LL, Blaser MJ, Reller LB (1981) Evaluation of transport and storage techniques for isolation of Campylobacter fetus subsp. jejuni from turkey cecal specimens. Journal of Clinical Microbiology 13(3): 438-443.

30. Turkson PK, Lindqvist KJ, Kapperud G (1988) Isolation of Campylobacter spp. and Yersinia enterocolitica from domestic animals and human patients in Kenya. Acta pathologica, microbiologica, et immunologica Scandinavica 96(2): 141-146.

31. Kaur T, Singh J, Huffman MA, Petrz elkova KJ, Taylor NS, et al. (2011) Campylobacter troglodytis sp. nov., Isolated from Feces of HumanHabituated Wild Chimpanzees (Pan troglodytes schweinfurthii) in Tanzania. Applied and Environmental Microbiology 77(7): 2366-2373.

32. De Boer RF, Ott A, Kesztyus B, Kooistra Smid AMD (2010) Improved Detection of Five Major Gastrointestinal Pathogens by Use of a Molecular Screening Approach. Journal of Clinical Microbiology 48(11): 4140-4146.

33. Persson S, De Boer RF, Kooistra-Smid AMD, Olsen KEP (2011) Five commercial DNA extraction systems tested and compared on a stool sample collection. Diagnostic Microbiology and Infectious Disease 69: 240-244.
34. Monteiro L, Bonnemaison D, Vekris A, Petry K, Bonnet J, et al. (1997) Complex polysaccharides as PCR inhibitors in feces: Helicobacter pylori model. Journal of Clinical Microbiology 35(4): 995-998.

35. Mutanda LN, Kangethe SK, Juma R, Lichenga EO, Gathecha C (1985) Aetiology of diarrhoea in malnourished children at Kenyatta National Hospital. East African Medical Journal 62(12): 835-841.

36. Shimotori S, Ehara M, Watanabe S, Ichinose Y, Waiyake PG, et al. (1986) Survey of Campylobacter jejuni and enterotoxigenic Escherichia coli in Kenya. Fukuoka Igaku Zasshi 77(11): 584-590.

37. Chunge RN, Wamola IA, Kinoti SN, Muttunga J, Mutanda LN, et al. (1989) Mixed infections in childhood diarrhoea: results of a community study in Kiambu District, Kenya. East African Medical Journal 66(11): 715723.

38. Kakai R, Wamola IA, Bwayo JJ, Ndinya-Achola JO (1995) Enteric pathogens in malnourished children with diarrhoea. East African Medical Journal 72(5): 8-9.

39. Saidi SM, Iijima Y, Sang WK, Mwangudza AK, Oundo JO, et al. (1997) Epidemiological study on infectious diarrheal diseases in children in a coastal rural area of Kenya. Microbiology and Immunology 41(10): 773-778.

40. Lastovica AJ, Engel ME, Blaser MJ (2003) A typical campylobacters and related organisms. In: Blaser MJ, Smith PD, Ravdin JI, Greenberg HB, Guerrant RL, editors. Infections of the gastrointestinal tract. $2^{\text {nd }}$ ed. Philadelphia: Lippincott Williams and Wilkins p. 741-761.

41. Nakari UM, Puhakka A, Siitonen A (2008) correct identification and discrimination between Campylobacter jejuni and C. coli by a standardized hippurate test and species-specific polymerase chain reaction. European Journal of Clinical Microbiology \& Infectious Diseases 27(7): 513-518.

42. Rönner AC, Lindmark H (2007) Quantitative detection of Campylobacter jejuni on fresh chicken carcasses by realtime PCR. Journal of Food Protection 70: 1373-1378.

43. Brooks JT, Ochieng JB, Kumar L, Okoth G, Shapiro RL, et al. (2006) Surveillance for Bacterial Diarrhea and Antimicrobial Resistance in Rural Western Kenya, 1997-2003. Clinical Infectious Diseases 43(4): 393-401.

44. Khalil K, GB Lindblom, K Mazhar, SR Khan, B Kaijser (1993) Early child health in Lahore, Pakistan: VIII. Microbiology. Acta Paediatr. 390: 8794.

45. Molbak K, Hojlyng N (1988) High prevalence of Campylobacter excretors among Liberian children related to environmental conditions. Epidemiology and Infection 100: 227-237.

46. Kaijser B (1988) Campylobacter jejuni/coli. Acta pathologica, microbiologica, et immunologica Scandinavica 96: 283-288.

47. Gascón J, Vargas M, Schellenberg D, Urassa H, Casals C, et al. (2000) Diarrhea in Children under 5 Years of Age from Ifakara, Tanzania: a Case-Control Study. Journal of Clinical Microbiol 38(12): 4459-4462.

48. Steele AD, Geyer A, Alexander JJ, Crewe-Brown HH, Fripp PJ (1988) Enteropathogens isolated from children with gastroenteritis at GaRankuwa Hospital, South Africa. Annals of tropical paediatrics 8(4): 262-267.

49. Ringertz S, Rockhill RC, Ringertz O, Sutomo A (1980) Campylobacter fetus subsp. jejuni as a cause of gastroenteritis in Jakarta, Indonesia. Journal of Clinical Microbiology 12: 538-540.

50. Haq JA, Rahman KM (1991) Camplylobacter jejuni as a cause of acute diarrhoea in children: a study at an urban hospital in Bangladesh. American Journal of Tropical Medicine and Hygiene 94(1): 50-54. 
51. Blaser MJ, Black RE, Duncan DJ, Amer J (1985) Campylobacter jejunispecific antibodies are elevated in healthy Bangladeshi children. Journal of Clinical Microbiology 21(2): 164-167.

52. Tadesse DA, Bahnson PB, Funk JA, Thakur S, Morrow WE, et al. (2011) Prevalence and Antimicrobial Resistance Profile of Campylobacter Spp. Isolated from Conventional and Antimicrobial-Free Swine Production Systems from Different U.S. Regions. Foodborne Pathogens and Disease 8(3): 367-374.

53. Fujita K, Kaku M, Yanagase Y, Ezaki T, Furuse K, et al. (1990) Physicochemical characteristics and flora of diarrhoeal and recovery faeces in children with acute gastro-enteritis in Kenya. Annals of tropical paediatrics 10(4): 339-345.

54. Joyce T, McGuigan KG, Elmore-Meegan M, Conroy RM (1996) Prevalence of enteropathogens in stools of rural Maasai children under five years of age in the Maasailand region of the Kenyan Rift Valley. East African Medical Journal 73(1): 59-62.

55. Beatty ME, Ochieng JB, Chege W, Kumar L, Okoth G, et al. (2009) Sporadic paediatric diarrhoeal illness in urban and rural sites in Nyanza Province, Kenya. East African Medical Journal 86(8): 387-398.

56. Mutanda LN, Patel A, Masudi AM, Maina G (1990) Aetiology of diarrhoea in pre-term neonates at Kenyatta National Hospital nursery, Nairobi, Kenya. East African Medical Journal 67(4): 223-230.

57. Jiwa SFH, Phiri ECJH, Kimera SI (1994) Isolation of thermophilic Campylobacter from clinically normal calves, goats, field mice and purging children at Sokoine University of Agriculture (SUA) campus, Morogoro, Tanzania. Tanz Veterinary Journal 14(3-4): 103-109.

58. Vargas M, Gascon J, Casals C, Schellenberg D, Urassa H, et al. (2004) Etiology of diarrhea in children less than five years of age in Ifakara, Tanzania. American Journal of Tropical Medicine and Hygiene 70(5): 536-539.

59. Kusiluka LJM, Karimuribo ED, Mdegela RH, Luoga EJ, Munishi PKT, et al. (2005) Prevalence and impact of water-borne zoonotic pathogens in water, cattle and humans in selected villages in Dodoma Rural and Bagamoyo districts, Tanzania. Physics and Chemistry of the Earth 30(11-16): 818-825.

60. Mshana SE, Joloba ML, Kakooza A, Kaddu-mulindwa D (2010) Role of microscopic examination of stool specimens in the diagnosis of campylobacter infection from children with acute diarrhoea in Kampala, Uganda. Tanzania Journal of Health Research 12(1): 100103.

61. De Mol P, Bosmans E (1978) Campylobacter enteritis in Central Africa. The Lancet 1(8064): 604.

62. De Mol P, Mets T, Lagasse R, Vandepitte J, Mutwewingabo A, etal. (1987) Treatment of bacillary dysentery: a comparison between enoxacin and nalidixic acid. Journal of Antimicrobial Chemotherapy 19(5): 695-698.

63. Clerinx J, Bogaerts J, Taelman H, Habyarimana JB, Nyirabareja A, et al. (1995) Chronic Diarrhea among Adults in Kigali, Rwanda: Association with Bacterial Enteropathogens, Rectocolonic Inflammation, and Human Immunodeficiency Virus Infection. Clinical Infectious Diseases 2(15): $1282-1284$.

64. Berrang ME, Buhr RJ, Cason JA, Dickens JA (2001) Broiler carcass contamination with Campylobacter from feces during defeathering. Journal of Food Protection 64(12): 2063-2066.

65. Hermans D, Van Deun K, Messens W, Martel A, Van Immerseel F, et al. (2011) Campylobacter control in poultry by currentintervention measures ineffective: urgent need for intensified fundamental research. Veterinary Microbiology 152(3-4): 219-228.
66. Crushell E, Harty S, Sharif F, Bourke B (2004) Enteric campylobacter: purging its secrets? Pediatric Research 55: 3-12.

67. Hermans D, Van Deun K, Martel A, Van Immerseel F, Messens W, et al. (2011) Colonization factors of Campylobacter jejuni in the chicken gut. Veterinary Research, pp. 42: 82.

68. Herman L, Heyndrickx M, Grijspeerdt K, Vandekerchove D, Rollier I, et al. (2003) Routes for Campylobacter contamination of poultry meat: epidemiological study from hatchery to slaughter house. Epidemiology and Infection 131: 1169-1180.

69. Jacobs-Reitsma WF (1997) Aspects of epidemiology of Campylobacter in poultry. Vet Quarterly 19(3): 113-117.

70. Nonga HE, Muhairwa AP (2009) Prevalence and antibiotic susceptibility of thermophilic Campylobacter isolates from free range domestic duck (Cairina moschata) in Morogoro municipality, Tanzania. Tropical Animal Health and Production 42(2): 165-172.

71. Jiwa SFH, Kazwala RR, Namahungu E (1994) Prevalence of Campylobacter spp. in clinically normal goats kept under various management systems in urban Tanzania. Small Ruminant Research 15: $97-100$

72. Komba EVG, Mdegela RH, Msoffe PLM, Matowo DE, Maro MJ (2014) Occurrence, species distribution and antimicrobial resistance of thermophilic isolates from farm and laboratory animals in Morogoro, Tanzania. Veterinary world 7(8): 559-565.

73. Boes J, Nersting L, Nielsen EM, Kranker S, Enoe C, et al. (2005) Prevalence and diversity of Campylobacter jejuni in pig herds on farms with and without cattle or poultry. Journal of Food Protection 68(4): 722-727.

74. Jensen AN, Dalsgaard A, Baggesen DL, Nielsen EM (2006) The occurrence and characterization of Campylobacter jejuni and Campylobacter coli in organic pigs and their outdoor environment. Veterinary Microbiology 116(1-3): 96-105.

75. Oporto B, Esteban JI, Aduriz G, Juste RA, Hurtado A (2007) Prevalence and strain diversity of thermophilic Campylobacters in cattle, sheep and swine farms. Journal of Applied Microbiology 103(4): 977-984.

76. Ogden ID, Dallas JF, MacRae M, Rotariu O, Reay KW, et al. (2009) Campylobacter excreted into the environment by animal sources: prevalence, concentration shed, and host association. Foodborne Pathogens and Disease 6(10): 1161-1170.

77. Harvey RB, Young CR, Ziprin RL, Hume ME, Genovese KJ, et al. (1999) Prevalence of Campylobacter spp. isolated from the intestinal tract of pigs raised in an integrated swine production system. Journal of the American Veterinary Medical Association 215(11): 1601-1604.

78. Young CR, Harvey R, Anderson R, Nisbet D, Stanker LH (2000) Enteric colonization following natural exposure to Campylobacter in pigs. Research in Veterinary Science 68(1): 75-78.

79. Leblanc-Maridor M, Beaudeau F, Seegers H, Denis M, Belloc C (2011) Rapid identification and quantification of Campylobacter coli and Campylobacter jejuni by real-time PCR in pure cultures and in complex samples. BMC Microbiology 11: 113.

80. Altekruse SF, Stern NJ, Fields PI, Swerdlow DL (1999) Campylobacter jejuni an emerging foodborne pathogen. Emerging Infectious Diseases 5(1): 28-35.

81. Luechtefeld NW, Reller LB, Blaser MJ, Wang WLL (1982) Comparison of atmospheres of incubation for primary isolation of Campylobacter fetus subspecies jejuni from animal species: $5 \%$ oxygen versus candle jar. Journal of Clinical Microbiology 15: 53-57. 
82. Waldenstrom J, Broman T, Carlsson I, Hasselquist D, Achterberg RP, et al. (2002) Prevalence of Campylobacter jejuni, Campylobacter lari, and Campylobacter coli in different ecological guilds and taxa of migrating birds. Applied and Environmental Microbiology 68: 5911-5917.

83. Adegbola RA, Alabi SA, Akinkuade FO, Coker AO, Odugbemi T (1990) Correlation between human and animal bioserogroups of Campylobacter isolates in Nigeria. Journal of Tropical Medicine and Hygiene 93(4): 280-283.

84. Rosef O (1981) The occurrence of Campylobacter fetus subsp. jejuni and Salmonella bacteria in some wild birds. Nord Veterinary Medical Journal 33(12): 539-543.

85. Ito K, Kubokura Y, Kaneko K, Totake Y, Ogawa M (1989) Occurrence of Campylobacter jejuni in free-living wild birds from Japan. Journal Wildlife Diseases 24(3): 467-470.

86. Saleha AA (2004) Epidemiological study on the colonization of chickens with Campylobacter in broiler farms in Malaysia: possible risk and management factors. International Journal of Poultry Science 3: $129-134$.

87. Genigeorgis C, Hassuneh M, Collins P (1986) Campylobacter jejuni infections on poultry farms and its effect on poultry meat contamination during slaughtering. Journal of Food Protection 49(11): 895-903.

88. Ngotho M, Ngure RM, Kamau DM, Kagira JM, Gichuki C, et al. (2006) A Fatal Outbreak of Campylobacter jejuni Enteritis in a Colony of Vervet Monkeys in Kenya. Scandinavian Journal of Laboratory Animal Science 33(4): 205-210.

89. Skirrow MB (1982) Campylobacter enteritis - the first five years. J Hyg (Lond) 89(2): 175-184.

90. Taema MM, Bull JC, Macgregor SK, Flach EJ, Boardman WS, et al. (2008) Retrospective Study of Campylobacter Infection in a Zoological Collection. Applied and Environmental Microbiology 74(5): 13321338.

91. Nizeyi JB, Innocent RB, Erume J, Kalema GRNN, Cranfield MR, et al. (2001) Campylobacteriosis, salmonellosis, and shigellosis in freeranging human-habituated mountain gorillas of Uganda. Journal of Wildlife Diseases 37(2): 239-244.

92. Kalema-Zikusoka G, Rothman JM, Fox MT (2005) Intestinal parasites and bacteria of mountain gorillas (Gorilla beringei beringei) in Bwindi Impenetrable National Park, Uganda. Primates 46(1): 59-63.

93. Steinhauserova I, Nebola M, Mikulicova M (2005) Prevalence of thermophilic Campylobacter species in slaughtered pigs in the Czech Republic, 2001-2003. Veterinary Medicine-Czech 50(4): 171-174.

94. Gannon VPJ (1999) Control of Escherichia coli 0157 at slaughter. In: Stewart, CS, and HJ Flint (eds), Escherichia coli 0157 in Farm Animals pp. 169-193.

95. Hakkinen M, Heiska H, Marja-Liisa H (2007) Prevalence of Campylobacter species in Cattle in Finland and Antimicrobial Susceptibilities of Bovine Campylobacter jejuni Strains. Applied Environmental Microbiology 73(10): 3232-3238.

96. Ono K, Yamamoto K (1999) Contamination of meat with Campylobacter jejuni in Saitama. International Journal of Food Microbiology 47(3): 211-219.

97. Beach JC, Murano EA, Acuff GR (2002) Prevalence of Salmonella and Campylobacter in beef cattle from transport to slaughter. Journal of Food Protection 65(11): 1687-1693.

98. Valnegri L, Franzoni M, Colombo F, Soncini G (2008) Isolation and identification of thermophilic Campylobacter species in cattle carcasses from a northern Italian slaughterhouse. Italian Journal of Food Science 20: 433-438.

99. Malakauskas M, Jorgensen K, Nielsen EM, Ojeniyi B, Olsen JE (2006) Isolation of Campylobacter species from a pig slaughterhouse and analysis of cross-contamination. International Journal of Food Microbiology 108(3): 295-300.

100. Kwiatek K, Wolton B, Stern NJ (1990) Prevalence and distribution of Campylobacter species on poultry and selected red meat carcasses in Poland. Journal of Food Protection 53: 127-130.

101. Ghafir Y, China B, Dierick K, De Zutter L, Daube G (2007) A seven-year survey of Campylobacter contamination in meat at different production stages in Belgium. International Journal of Food Microbiology 116(1): 111-120.

102. Lindblad M, Lindmark H, Lambertz ST, Lindqvist $\mathrm{R}$ (2007) Microbiological baseline study of swine carcasses at Swedish slaughterhouses. Journal of Food Protection 70(8): 1790-1798.

103. Hudson JA, Nicol C, Wright J, Whyte R, Hasell SK (1999) Seasonal variation of Campylobacter types from human cases, veterinary cases, raw chicken, milk and water. Journal Applied Microbiology 87: 115124.

104. Nylen G, Dunstan F, Palmer SR, Andersson Y, Bager F, et al. (2002) The seasonal distribution of Campylobacter infection in nine European countries and New Zealand. Epidemiology and Infection 128(3): 383390 .

105. Patrick ME, Christensen LE, Waino M, Ethelberg S, Madsen H, et al. (2004) Effects of climate on incidence of Campylobacter spp. in humans and prevalence in broiler flocks in Denmark. Applied and Environmental Microbiology 70(12): 7474-7480.

106. Kovats RS, Edwards SJ, Charron D, Cowden J, D’Souza RM, et al. (2005) Climate variability and Campylobacter infection: An international study. International Journal of Biometeorology 49(4): 207-214.

107. Meldrum RJ, Griffiths JK, Smith RM, Esnas MR (2005) The seasonality of human Campylobacter infection and Campylobacter isolates from fresh, retail chicken in Wales. Epidemiology and Infection 133(1): 4952.

108. Berndtson E, Emanuelsson U, Engvall A, Danielsson-Tham M-L (1996) A one-year epidemiological study of Campylobacter in 18 Swedish chicken farms. Preventive Veterinary Medicine 26: 167-185.

109. Wedderkopp A, Rattenborg E, Madsen M (2000) National surveillance of Campylobacter in broilers at slaughter in Denmark (1998) Avian Diseases 44: 993-999.

110. Wilson IG (2002) Salmonella and campylobacter contamination of raw retail chickens from different producers: a six-year survey. Epidemiology and Infection 129(3): 635-645.

111. Evans MC, Christiansen LE, Wedderkop A, Gerner- Smidt P, Wegener HC (2002) Effects of climate on Campylobacter species in humans and broilers in Denmark. In: Abstracts of the 3rd International Conference on Emerging Infectious Diseases. Atlanta: 20-24 March 2002 (board 65). Centers for Disease Control and Prevention. Atlanta, Georgia.

112. Bang DD, Nielsen EM, Knudsen K, Madsen M (2003) A one year study of Campylobacter carriage by individual Danish broiler chickens as the basis for selection of Campylobacter species strains for a chicken infection model. Epidemiology Infection 130(2): 320-323.

113. Bouwknegt M, Van De Giessen AW, Dam-Deisz WDC, Havelaar AH, Nagelkerke NJD, et al. (2004) Risk factors for the presence of Campylobacter spp. in Dutch broiler flocks. Preventive Veterinary Medicine 62(1): 35-49. 
114. Hansson I, Engvall EO, Lindblad J, Gunnarson A, Vågsholm I (2004) The Campylobacter surveillance program for broilers in Sweden, July 2001June 2002. Veterinary Record 155: 193-196.

115. Hofshagen M, Kruse $H$ (2005) Reduction in flock prevalence of Campylobacter spp. in broilers in Norway after implementation of an action plan. Journal of Food Protection 68(10): 2220-2223.

116. Kang YS, Cho YS, Yoon SK, Yu MA, Kim CM, et al. (2006) Prevalence and antimicrobial resistance of Campylobacter jejuni and Campylobacter coli isolated from raw chicken and human stools in Korea. Journal of Food Protection 69(12): 2915-2923.

117. Jore S, Viljugrein H, Brun E, Heier BT, Borck Ethelberg S, et al. (2010) Trends in Campylobacter incidence in broilers and humans in six European countries, 1997-2007. Preventive Veterinary Medicine 93(1): 33-41.

118. Ishihara K, Takahashi R, Andoh M, Ueno H, Muramatsu Y, et al. (2012) Seasonal variation in Campylobacter-contaminated retail chicken products: a year-round investigation in Japan. Journal of Veterinary Medical Science 74(1): 117-120.

119. Blaser MJ, Reller LB (1981) Campylobacter Enteritis. New England Journal of Medicine 305(24): 1444-1452.

120. Aarestrup FM, Wegener HC (1999) The effects of antibiotic usage in food animals on the development of antimicrobial resistance of importance for humans in Campylobacter and Escherichia coli. Microbes and Infection 1(8): 639-644.

121. Aarestrup FM, Engbergb J (2001) Antimicrobial resistance of thermophilic Campylobacter. Veterinary Research 32(3-4): 311-321.

122. Padungton P, Kaneene JB (2003) Campylobacter species in human, chickens, pigs and their antimicrobial resistance. Journal of Veterinary Medical Science 65(2): 161-170.

123. Sack DA, Lyke C, McLaughlin C, Suwanvanichkij V (2001) Review of Campylobacter. In: Antimicrobial resistance in Shigellosis, Cholera and
Campylobacteriosis, World Health Organization (WHO), Switzerland: 31-50.

124. Ruiz J, Goñi P, Marco F, Gallardo F, Mirelis B, et al. (1998) Increased resistance to quinolones in Campylobacter jejuni: a genetic analysis of gyrA gene mutations in quinolone-resistant clinical isolates. Microbiology and Immunology 42(3): 223-226.

125. Saenz Y, Zarazaga M, Lantero M, Gastanares MJ, Baquero F, et al. (2000) Antibiotic resistance in Campylobacter strains isolated from animals, foods, and humans in Spain in 1997-1998. Antimicrobial Agents and Chemotherapy 44(2): 267-271.

126. Chu YW, Chu MY, Luey KY, Ngan YW, Tsang KL, et al. (2004) Genetic relatedness and quinolone resistance of Campylobacter jejuni strains isolated in 2002 in Hong Kong. Jornal of Clinical Microbiology 42(7): 3321-3323.

127. Jain D, Sinha S, Prasad KN, Pandey CM (2005) Campylobacter species and drug resistance in a north Indian rural community. Transactions of the Royal Society of Tropical Medicine and Hygiene 99: 207-214.

128. Gaudreau C, Gilbert H (2003) Antimicrobial resistance of Campylobacter jejuni subsp. jejuni strains isolated from humans in 1998 to 2001 in Montreal, Canada. Antimicrobial Agents and Chemotherapy 47(6): 2027-2029.

129. Senok A, Yousif A, Mazi W, Sharaf E, Bindayna K, et al. (2007) Pattern of antibiotic susceptibility in Campylobacter jejuni isolates of human and poultry origin. Japanese journal of infectious diseases 60(1): 1-4.

130. Mazi W, Senok A, Al-Mahmeed A, Arzese A, Bindayna K, et al. (2008) Trends in antibiotic sensitivity pattern and molecular detection of tet(0)-mediated tetracycline resistance in Campylobacter jejuni isolates from human and poultry sources. Japanese journal of infectious diseases 61(1): 82-84.

131. Avrain L, Vernozy-Rozand C, Kempf I (2004) Evidence for natural horizontal transfer of tet0 gene between Campylobacter jejuni strains in chickens. Journal of Applied Microbiology 97(1): 134-140.

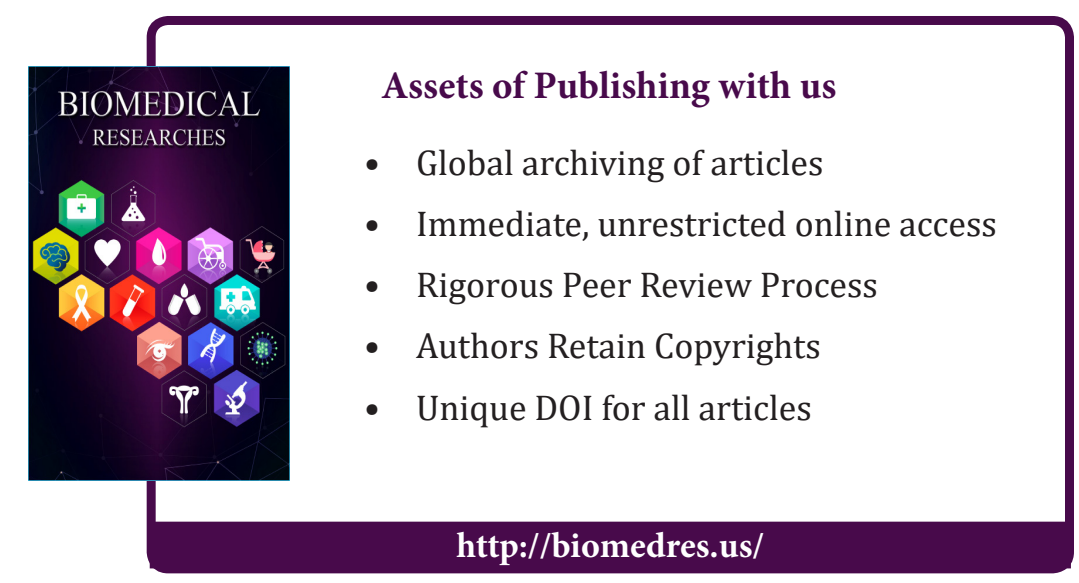

